THURSDAY, APRIL 4, I872

\section{THE FOUNDATION OF ZOOLOGICAL STATIONS}

\section{II.-The Aquarium at Naples}

WHEN I wrote the first article on the "The Foundation of Zoological Stations,"* I desired to bring before the general public the idea of extending the principle of co-operation in Science in general, and in Biology in particular. I now propose to give a sketch of the internal organisation of a zoological station as it presents itself to my mind. It is natural that in doing this I give more or less a picture of what $I$ intend to produce at the station which is at present being erected under my superintendence at Naples.

The building occupies an area of 7,000 square feet, and is situated at a very short distance-rooft.-from the sea. It forms a rectangle rooft. long and 7 oft. broad, with a height of 4 oft. The building is divided into two parts, the lower part being occupied by the tanks of the great aquarium, which is to be open to the public; the upper part containing twenty-four rooms of different sizes for laboratories, a library, and collections, and for lodging the three or four zoologists who will be constantly occupied in managing the station.

I will not speak here of the manner in which the technical parts of the aquarium are to be arranged, as this would scarcely interest my readers. What I should like to specialise a litile relates more to the facilities for scientific study which the station will afford.

Let me speak first of the lower part of the building, the great public aquarium. It will contain fifty-three tanks of different sizes, one of them $32 \mathrm{ft}$. long, Ioft. broad, and $3 \mathrm{ft}$. to $6 \mathrm{ft}$. deep; twenty-six $6 \mathrm{ft}$. 6in. long, and equally broad; and twenty-six others $3 \mathrm{ft}$. long and $3 \mathrm{ft}$. to $6 \mathrm{ft}$. broad. These tanks will contain marine animals of all kinds, either isolated or more or less mixed, according to the investigations that are to be made.

I imagine now that in one of these tanks a number of Medusæ and Salpæ are together, and the problem is to know how they will behave in so close a union. This can be solved only in such a tank, and it will be a very easy study, as the naturalist has only to occupy a movable chair, which is placed before the tank, and which hides him and the tank by special precautions completely from the general public. At a certain moment you can put into the tank some rapacious fishes, or some of the swift and warlike Crustaceans of the Palæmon tribe, and wait for the movements and actions of the Medusæ as well as the Salpæ. You may repeat these observations, and add other different species; and if you have patience enough, you cannot fail to discover facts about the general habits of the animals in question, and the functions of their organs, which were unknown before, and which may yield, perhaps, valuable arguments to establish a theory on the manner in which they originated from other animals. As it is, we hardly know anything about the life of Medusæ or Salpæ, and our ignorance of the habits of other marine animals is equally great.

* Nature, vol, v. p. 277 .
Let us take another example. I was present when halt a dozen stone crabs (Lithodes Maya) were brought from Norway to the Hamburg Aquarium. Mr. Lloyd, at that time the Director of the Aquarium, distributed them in several tanks. It happened that one of them found itself in company with a number of Crerilabrus norwegicus, a swift and clever little fish. These at once began to attack their new companion. With considerable skill they tried to hurt the eyes of the crab, which on their long stalks presented, of course, the most vulnerable part of the clumsy and spinous animal. After half an hour's continued attacks the fishes actually succeeded in tearing out one of the eyes. This fact made me investigate at once the mode of protection with which Nature had furnished the eyes of Crustacea, and I collected a considerable number of observations, which, if completed and worked out, would possibly form a very interesting chapter in our knowledge of the progress of Natural Selection.

I shall adduce a third instance for the necessity of facilitating observations of this kind. In his excellent refutation of some of $\mathrm{Mr}$. Mivart's objections to the theory of Natural Selection, Mr. Darwin relates ("Origin of Species," 6th Edition, p. I86) some observations made by Malm on the way in which the eyes of the Pleuronectes get both on one side of fish. The folIowing are his words :-

"The Pleuronectidæ, whilst very young and still symmetrical, with their eyes standing on opposite sides of the head, cannot long retain a vertical position, owing to the excessive depth of their bodies, the small size of their Jateral fins, and to their being destitute of a swim-bladder. Hence, soon growing tired, they fall to the bottom on one side. Whilst thus at rest they often twist, as Malm observed, the lower eye upwards, to see above them; and they do this so vigorously that the eye is pressed hard against the upper part of the orbit. The forehead between the eyes consequently becomes, as could be plainly seen, temporarily contracted in breadth. On one occasion Malm saw a young fish raise and depress the lower eye through an angular distance of about seventy degrees. We should remember that the skull at this early age is cartilaginous and flexible, so that it readily yields to muscular action. Besides, Malm states that the newlyhatched young of perches, salmon, and several other symmetrical fishes, have the habit of occasionally resting on one side at the bottom; and he has observed that they often then strain their lower eyes so as to look upwards and their skulls are thus rendered rather crooked. These fishes, however, are soon able to hold themselves in a vertical position, and no permanent effect is thus produced. With the Pleuronectidæ, on the other hand, the older they grow the more habitually they rest on one side, owing to the increasing flatness of their bodies, and a permanent effect is thus produced on the form of the head and on the position of the eyes."

I think observations of this kind ought to speak so much in favour of a great observatory for marine animals, that it would be superfluous to add any more instances for its necessity. I hope the Naples Institution will rapidly produce a great number of similar observations, and thus render one of the most important services to the still utterly neglected knowledge of the animal life of the ocean.

Let us now ascend the staircase from the lower part of the future Zoological Station to the upper floor. We pass through a series of rooms on the north side, the first of 
which is occupied by the chief zoologist. Before the window a table for microscopical work is placed, surrounded by small tanks for breeding eggs and keeping alive larvæ and other smaller animals. Each tank is furnished with a continuous current of fresh sea-water, which can be weakened or strengthened, or completely stopped, as it pleases the zoologist. The rest of the room is reserved for the business matters of the station. Next to it comes the library-room, large enough to keep a library of 25,000 volumes. Two tables for microscopical work placed near one another occupy the place near the window, some tanks of different sizes, completely furnished with tubes, \&c., are placed at the disposal of those who occupy the tables. Next follows the great laboratory. In the centre of the room we find at least twenty to thirty tanks of different sizes, each of them with its own current of sea-water; the two great front windows afford light for four working tables placed near them. The walls may be occupied by physiological instruments and by other apparatus which will be required. Galleries on the walls and across the centre of the room yield enough space for placing all sorts of collections and other things on them without hindering the free passage in the laboratory. The last room on this northern side will be occupied by the first assistant zoologist, and be furnished, like that of the chief zoologist, with working table and tanks. Both the corners of the house are occupied by towers, and these towers contain two small chambers of nine feet square; they are also to be furnished with tables and some tanks, so that in all ten zoologists may, at the same time, find complete accommodation for their work.

The south side of the upper part of the station will be occupied by four rooms, sufficiently large to allow the collections to increase for many years, and the laboratory to take possession of double the space it will occupy at the beginning. The west and east side afford some private rooms for the use of the naturalists employed in the management of the station. Under the roof eight other smaller rooms complete the whole disposition of the space inside the building.

Now let me say some words on the functions these organs of the Zoological Station are to exhibit in future. There are first to be noticed the great advantages which will be offered to the single student. Whoever works with marine animals will be painfully acquainted with the difficulty of preserving them alive longer than two or four days. They almost invariably die, and decompose very soon. If one now considers that anatomical and stil more embryological problems are only to be solved during weeks or months of undisturbed and indefatigable exertion, it is quite evident what enormous advantage must result from the possibility of keeping these animals alive during weeks. And this will " be effected by the help of tanks with a continuous stream of sea-water. The sea being always in motion, caused either by the waves or still more by the vast number of currents, makes the constant alternation of fresh and aerrated sea-water necessary for the life of the animals. The imitation of these currents and the artificial injection of air into the tanks will render it possible to keep even embryos and larvæ alive, which formerly could never be studied on account of their early death.

Besides, everybody knows how often fishermen bring eggs or larva which are completely unknown to the zoologist. They are, perhaps, highly interesting ; perhaps belonging to animals whose eggs have never been seen before, as they deposit them far off in the open sea or on the bottom. The single zoologist in his small room in a Naples Hotel, with some bottles or basins at his disposal, puts them into a tumbler, changes the water regularly, and thus succeeds in keeping them alive for a week, but he forgets the changing once, and to-morrow they are dead. A good many will even not live in spite of the changing of the water, because they require the constant stream running over them. The single zoologist in the station, on the other hand, puts them into a tank, sets the stream in motion, and has nothing to do but to watch their development, and the final disclosure of the embryo, or the metamorphoses of the larva, and may completely succeed in getting a key to their nature and their relation to other animals.

Considering now the all-importance of embryology and development in the present state of zoology, it is easy to recognise in the continuous stream of the sea-water in the station a fundamental novelty in the conditions for the progress of scientific zoology. Go a little further. It is rarely advisable to work with one subject alone when on the sea-coast. There are so many incidents that change the conditions of the work you have in hand, that you are much wiser to have, whilst working at one chief problem, one or two smaller ones with it. But chance is often a paradoxical thing ; it will entirely inundate you one day with excellent material for all these problems, and cause you great embarrassment as to what to take first; and another day it will yield you nothing whatever, so as to force you to idleness. Now again with a series of tanks and streaming sea-water you can pursue everything quite at your leisure, stop one investigation when you like, or take up another, or drop them both, and work for one day with some interesting novelty, without being afraid of spoiling the material of the old objects, and losing the opportunity of getting through it. And everybody knows what a consolation it is to be always capable of taking your principal line of work up again, whilst you are not forced to deny yourself the chance of taking some notice of new arrivals, if it even were only for a little instructive side glance of some hours.

These are some illustrations of the great facilities and advantages of the station, yielding thus in future to scientific workers immense economy of time, money, and power. But this is not all that the station will do. Every wellinstructed biologist is aware of the great step anatomical science made when first Cuvier created and afterwards Johannes Müller reformed Comparative Anatomy. The description of the different types, the organs and their homologies, their histological constitution, similarity and dissimilarity, became well worked out, and extended the range of our insight over almost all living animals.

Physiology ought to have gone the same length, following exactly the lines of anatomical research, to tell us something about the functions of all the organs and 
structures through the whole range of animal life. But physiology did not do so ; it got into another line, investigating with the utmost care, and also with splendid success, the nervous functions of the higher vertebrates, developing theories on the physical agency of these functions, and trying to verify these theories by experiments. It went also into chemical researches, trying to get clear insight into the chemical processes of digestion and the nourishment of the body of the higher vertebrates. In consequence of this one- or rather two-sidedness, it has happened that physiology appears to be very indifferent to the great overthrow of our views regarding the organic world, caused by the doctrine of evolution. Indeed, celebrated physiologists even go so far as to deny the truth of that doctrine altogether. Now nothing can be a stronger proof that there is something amiss in the state of physiology, and this something consists in the complete want of Comparative Physiology. If we cannot understand the anatomical constitution of men and the higher animals without the study of comparative anatomy and embryology, we can equally as little understand their physiological components if we do not follow them up through the whole series of animal life. It is utterly deplorable that so very little has been done in this immense department of Science, What do we know of the functions of such all-important organs as the so-called segmental organs of Annelids, which in the further development of other classes of the animal kingdom grew into some possessing the highest functions? Nobody doubts that Amphioxus is a Vertebrate ; but has any one yet tried to make physiological experiments with that animal, though it is one of the most hard-living of all marine animals? And is there in any way a 'base laid for the physiology of fishes, which must yield results of the utmost importance? Does the academical physiology of modern times do the least to unveil the mysteries of generation, of growth, of degeneration? Are these departments, perhaps, less interesting, less important, less accessible than Nervous Physiology or the Physiology of Digestion?. There is apparently a lack of idea in this great department of Biology, an overgrowing influence of Physicists, and a want of morphological knowledge among Physiologists. What would have been the fate of Physiology if, unfortunately, Johannes Muiller had not died in the same year when the "Origin of Species" came out? He was the man to create at once the study of Comparative Physiology, and his spirit must again come over physiologists to enable them to perceive the immense field of action before them, and the neglect with which they treat it.

Now, I can only say that it is one of the great objects of the Naples station to do all in its power to carry on a fair commencement of Comparative Physiology. Whatever money may be spared, whatever pains bestowed, it will willingly be given to so important a duty, and it would be considered a great good fortune should a thoroughly instructed physiologist make up his mind to accept a post in the station in order to establish and carry on a Physiological Laboratory.

To all the possible advantages of the station for the intermittent action of single naturalists alluded to above, unite now the great advantage from the fact that such isolated action will be quite superseded. A station like that of Naples wants at least three well-trained zoologists to conduct it properiy. One of the greatest privileges for these zoologists will certainly be that teaching forms no essential part of their duties. Whoever knows by experience what a loss of energy: and of time is caused to all those original workers who are bound to teach daily on elementary topics, what great relief vacations form in the life of university professors and privat-docents (who generally proceed with original work daily during their vacations), will be aware of the exceeding value of paid places where teaching is no necessity, and is only admitted for single and special puposes. The comfortable system of English fellowships, granting money to young gentlemen who are supposed to merit special rewards by having undergone some examinations, will, in fact, be united to the principle of Continental academies, of paying men of scientific reputation, that they may go on at their leisure with original scientific work. The zoologists in the stations will be selected from the number of young professors or privat-docents, who, as a matter of course, are supposed to be ambitious to do some good things in science, even at the risk of sacrificing comfort and agreeable social life. They will be sufficiently paid, and their payment even raised so as to equal that of a moderatelypaid German university professor; though perhaps not approaching the level of the payment of a young Oxford or Cambridge Fellow. Nevertheless, they will be put in a position to balance that inferiority by making themselves known as workers, and adding to the storehouse of science facts and observations which may secure to them, if not a comfortable position in life, yet at least applause and respect from the eminent men of their science.

And these zoologists, having at their disposal a laboratory of the perfection and extent of the future Naples one, being aided by the possession of an all but complete biological library, and having before their doors the immense storehouse of the Mediterranean Sea, cannot fail to effect a great step in organising the progress of biological work. Let us suppose the question arose whether Cephalopods preceded in geological time other Molluscs, or were a higher developed offspring of them. The problem would be completely insoluble to University zoologists. But the three zoologists of the station at Naples would at once proceed with a solution in working out the embryology of the seven or eight species occurring in the Gulf, communicating and controlling each other's observations and conclusions. Some foreign zoologists might join their labours for half a year, and Science would be at once in possession of some thoroughly worked out contributions to the Comparative Embryology of the Cephalopods. Apply the same system of co-operation to other problems, for instance to one the solution of which is so much longed for, as the Embryology of Sharks. Years will not enable a single worker to go through that enormous task, with the sole aid of his individual opportunities. But suppose the leading zoologist of the station got the plan into his head to carry out the solution of this problem. He invites some excellent zoologist who completely understands the problem to come to Naples, to bring with him two or three assistants who have already beforehand been made acquainted with the object of the inquiry and the chief difficulties of the observation, and to set to work from 
the very first day of their arrival. He himself will do all in his power to procure every day fresh material of all kinds; by the help of the small steam yacht of the station he may succeed in carrying over to the station sharks which were taken two hours before, so as to secure the life of the embryos without any danger of destruction. Then he can isolate and feed them, and make them live as long as he wants. Any one who knows the fauna of the Mediterranean knows also what a large number of different species of rays and sharks arrive in it, and all these could be readily placed at the disposal of the embryologists, thus enabling them to overcome at once immense difficulties which have hitherto been almost completely unassailable.

The station will have several people, fishermen or guards, who by-and-by will be completely acquainted with the fauna of the bay, and will be able to collect whatever is necessary. As very often rare or muchwanted animals come in with some current in great quantities and disappear even the next day, such animals may at once be taken in great numbers and distributed through a great number of tanks, so as to keep them alive for future time.

Very often zoologists from the Universities have just four or six weeks' leisure, and would very much like to do some original work on the shores of the Mediterranean. But to go there for so short a period, to lose so much time in getting up all the necessary arrangements, and spend so much money for so small and uncertain scientific profit, is rather inadvisable for those who have to live on small incomes. But suppose the station is ready, zoologists announce some weeks beforehand their intention to come to Naples, and to work with this or that object, what is easier and what more comfortable than to arrive at the fixed date, to find lodging, laboratory, library, and material all ready and in the very best state, and to go over a ground of scientific work in six weeks, which otherwise would, perhaps, have occupied three months.

And will not the establishment of the Naples Station enable even those to come and work there, who (like many of the very best German and foreign zoologists) do not command means large enough even for a stay of two or three months at their own expense? Will not the constant presence and the collected experience of the stationzoologists save the foreign naturalists all the trouble and annoyance which inevitably result to every one who is not well acquainted with the ways and modes of life and customs of a place so complicated, and in every way so strange, as Naples? And, on the other side, will not the presence of the three station zoologists guarantee Science that it shallnot lose the fruits of all that work which was begun but could not be finished by foreign zoologists, since their teaching duties forced them to go home and leave it uncompleted behind? Easily enough one of the station zoologists takes it up and carries it on to a point where it may be fit for publication, thus preserving the labour and energy spent on it.

But I could continue preaching and preaching on a chapter which ought to be clear to every one who understands the progress of Science. I trust that what has been said is sufficient to procure the assistance of all those who think it a pity that whilst millions and. millions are accumulated for the pleasure of individuals who very often do not care a bit for the welfare or the progress of their fellow creatures, schemes like the present, so evidently adapted for throwing open new lines of inquiry into the mystery of the universe, and by that means adding to human progress and happiness, should be abandoned to chance and to isolated individual goodwill and effort.

Naples, March 9

ANTON DOHRN

\section{SCROPE ON VOLCANOS}

Volcanos. By G. Poulett Scrope, F.R.S., \&c. Second Edition revised and enlarged. With Prefatory Remarks. (London : Longmans, 1872.)

THE subject of volcanos is one which possesses a popular as well as a purely scientific interest, and the more so of late years, since it seldom happens that the foreign mails come in without bringing us tidings of volcanic outbursts or earthquake shocks, often fearfully disastrous, which have occurred in some one or other part of the globe; so that it is but natural to expect that the appearance of a revised and enlarged reissue of the second edition of the well-known work on volcanos by the distinguished and veteran geologist Mr. Poulett Scrope, will attract the attention, not only of geologists, but of the scientifically inclined public in general.

It is not saying too much, when we express our opinion that no geological library can ba considered complete without Mr. Poulett Scrope's work; but at the same time it is fairly open to question as to whether this volume in its present form can in 1872 be regarded as an improvement upon what it was before in 1862 ; since, with the exception of a list of the earthquakes and volcanic eruptions which have occurred since the year I 860 , the additional matter, introduced into it as a sort of postscriptum preface, is of a purely discursive and theoretical character, and for various reasons not likely to meet with that general acceptance, from those posted up to date in the subject, which the mass of excellent observational and descriptive matter embodied in the book itself is fully entitled to.

To render full justice to Mr. Poulett Scrope as a vulcanologist, we must however, carry ourselves back nearly half a century, to the time when the first edition of this work appeared in print; for it is only by so doing that we can be enabled to thoroughly appreciate the importance of his labours in the study of these wonderful phenomena, or to understand how largely they contributed to bring about the substitution of sounder doctrines concerning the formation and structure of volcanos, instead of the very. erroneous, yet all but universally received hypotheses, which at that time were taught in the schools of natural science.

If now we proceed to analyse the contents of the volume before us, its perusal will soon show that it devotes itself exclusively to the consideration of the subject treated only from a purely physical and geographical point of view, and as such, it must be admitted to be a most elaborate digest of what is known relating to what may be termed the mechanics of volcanos, their physical structure, and their local distribution over the surface of the 